\title{
DETECTION OF FAULTS IN THE ASYNCHRONOUS MACHINE BY THE USE OF SMARTMATERIALS
}

\author{
Amar REGAZ ${ }^{1}$, Boubakeur ZEGNINI ${ }^{1}$, Djelali MAHI ${ }^{1}$, Larbi BOUKEZZI $^{2}$ \\ ${ }^{1}$ Laboratory of studies and Development of Semiconductor and Dielectric Materials, LeDMaScD, \\ University Amar Telidji of Laghouat, BP 37G route of Ghardaïa, Laghouat 03000, Algeria. \\ e-mails: a_regaz@yahoo.fr, b.zegnini@lagh-univ.dz, d.mahi@lagh-univ.dz \\ ${ }^{2}$ Materials Science and Informatics Laboratory, MSIL, Ziane Achour University of Djelfa, \\ PO Box 3117 Road Moudjbara, 17000 Djelfa, Algeria, e-mail:larbiboukezzi@gmail.com
}

\begin{abstract}
This paper aimed with diagnosis of defects in asynchronous machine. The used method is based on the exploitation of the behavioural laws of magnetostrictive and piezoelectric materials, under harmonic regime, used in the construction of the asynchronous machine. Piezoelectric sensors are used both in the stator and in the rotor. The used one in the stator serves to detect the rupture at the stator windings and the one used in the rotor helps us to detect the rupture of the rotor bars. The produced electric potential in the terminals of piezoelectric sensor is due to the deformation generated by magnetic induction under the effect of magnetostriction. A finite element method (FEM) is selected to be the resolution numerical method. This method is used for modelling the asynchronous machine under anomaly conditions and non-load.
\end{abstract}

Keywords: Piezoelectric, Magnetostrictive, Diagnosis, asynchronous machine.

\section{INTRODUCTION}

The three-phase asynchronous machine is widely used in industrial applications because its relatively simple design, its cost is relatively lower than the other machines, its robustness at the electromagnetic level is great, and a good standardization exists between the different manufacturers. Therefore, the detection of defects in these types of machines is requested and has a great benefit for the manufacturers and the users. During the operation of these machines there are often a lot of defects that can be occurred. Among them we can cite: power supply phase interruptions and winding breaks in the stator or bars in the rotor. These are considered as major and harmful electrical and mechanical defects in electrical machines and can also lead to eccentricity faults [1].

Breaking in rotor bars can cause many serious concerns in the asynchronous machine operating. The reduction in the machine efficiency, the localized rotor heating and more importantly the rotor vibration due to the rotor expansion and bowing are the main concerns that can be found. Hence, a lot of approaches have been proposed in the literature trying to detect and analyse the broken rotor bars signature [2]-[8]. The first approach is based on the involving of the stator currents to analyze the broken rotor bars [9]. However, this approach represents some limitations reported in [10]-[12]. Another approach is based on the use of Artificial Neural
Networks. This tool is used successfully by Sadeghian et al. [13] in the detection of broken rotor bars under reduced load conditions.

The work of [9] used an electrical circuit model. In this model, the currents in the broken bar are cancelled and the flow currents in the adjacent bars are increased. However, these bars can be only degraded but not completely broken and this state can be modelled with a low electrical conductivity of the corresponding bar [14] or by a high resistance in which increases the resistance of the rotor bar [9]. Secondly, they are definitely broken by zero electrical conductivity [14].

In this work, we have presented a new approach based on the use of the so-called smart or active materials. Our idea is based on the exploitation of the piezo-magnetic materials properties that makeup the stator and the rotor of asynchronous machines. These active materials are used as smart sensors to record different signals. One of the important studies in the field of smart materials are presented in [15]-[17] where the behaviour of weakly magnetostrictive ferromagnetic sheets (FeSi, FeCo,..etc.) under uni-axial solicitations is studied. Another fundamental works that must be considered are those published [18]-[20] that concern mainly consideration of the state of multiaxial constraints on the magnetic behaviour. The presence of a magnetic field causes deformation in these materials which is transmitted to the piezoelectric material. This deformation is the origin of an electric polarization. It is the direct piezoelectric effect, which corresponds to the 
electric polarization of the material under the action of a mechanical stress [21], [22]. The formulation of the electromechanical and magneto-mechanical problem takes into account the coupling phenomena through the piezoelectric and piezo-magnetic behaviour laws. The formulation associated with this problem can be obtained from the minimization of the functional energy. A finite element method FEM is selected to be the resolution numerical method. This method is a more powerful and versatile numerical technique for handling problems involving complex geometries and inhomogeneous media. In our previous work on piezoelectric materials we have contributed by the creation of a toolbox 3D under environment Matlab for analysis the 3D FEM time harmonic problems in piezoelectric materials [23][24]. Another toolbox created also by us [25] specialized in the analysis of magnetostrictive materials. In this paper both created toolbox coupling between them will be used to diagnosis and detect defects in the asynchronous machines.

\section{PARAMETERS AND GEOMETRY OF THE ASYNCHRONOUS MACHINE}

The studied asynchronous machine has four poles and consists of a stator containing thirty-six slots in which are placed the windings connected to the three-phase voltage source. The rotor is a squirrel cage rotor type includes twenty-eight aluminium bus bars. The air gap was a quarter of a millimeter as presented in Fig. 1.

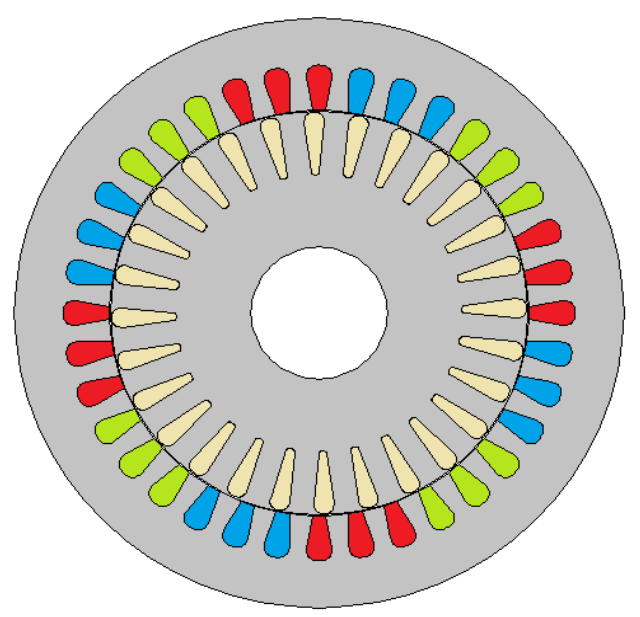

Fig. 1. Geometry of asynchronous machine

\section{BEHAVIORAL LAWS}

The stator generally consists of Fe-3\% Si steel sheets with non-oriented grains which act as a channel for the magnetic flux, and it also carries supply windings. The ferromagnetic materials exhibit a strong magneto-mechanical coupling between the magnetic induction and the deformation. The existing coupling can be represented by the following behaviour tensors [26]:

$$
\begin{aligned}
& \{\varepsilon\}=\left[s^{H}\right]\{\sigma\}+[d]\{H\} \\
& \{B\}=[d]\{\sigma\}+\left[\mu^{\sigma}\right]\{H\}
\end{aligned}
$$

With:

$\varepsilon$ : strain, $\sigma$ : stress, $H$ : magnetic field and $B$ : magnetic induction.

$\mu^{\sigma}$ : tensor of magnetic permeability of material under a constant mechanical stress.

$s^{H}$ : tensor of mechanical elasticity under a constant magnetic field.

$d$ : magneto-mechanical coupling tensor under a stress and a given magnetic field.

Ceramics such as PZT-5H are used as piezoelectric sensors and have a strong electromechanical coupling that can be expressed by the behaviour tensors [27] [28]:

$$
\begin{aligned}
& \{\varepsilon\}=\left[s^{E}\right]\{\sigma\}+[e]\{E\} \\
& \{D\}=[e]\{\sigma\}+\left[\xi^{\sigma}\right]\{E\}
\end{aligned}
$$

With:

$\varepsilon$ : deformation, $\sigma$ : stress, $E$ : electric field and $D$ : electrical induction.

$s^{E}$ : tensor of mechanical elasticity under a constant electric field.

$\xi^{\sigma}$ : tensor of electrical permittivity of material under a constant mechanical stress.

$e$ : Electro-mechanical coupling tensor under a stress and a given electric field.

In the air-gap and the stator windings the magnetic induction is proportional to the magnetic field as in (5).

$$
B=\mu_{0} H
$$

With:

$\mu_{0}$ : permeability of a vacuum is equal $4 \pi \cdot 10^{-7} \mathrm{H} / \mathrm{m}$.

The rotor bars present the birth of the induced currents so:

$$
\left\{J_{\text {ind }}\right\}=[o]\{E\}
$$

With:

$J_{\text {ind }}$ induced electric currents, $o$ : electrical conductivity.

\section{FINITE ELEMENTS FORMULATION}

\subsection{Piezomagnetic}

In the domain of magnetostrictive material, the magneto-mechanical problem can be formalized by the following equations:

$$
\begin{aligned}
& j o \omega A+\nabla \times \frac{1}{\mu^{\sigma}}\left(\nabla \times A-d^{\prime} s^{H^{-1}} \varepsilon\right)=J_{e x t}(7) \\
& \rho \omega^{2} U+\nabla \bullet \frac{1}{s^{\prime H}}\left(\varepsilon-\frac{d}{\mu^{\sigma}} B\right)=0
\end{aligned}
$$

with: $A$ : Magnetic vector Potential, $J_{\text {ext }}$ : external current density, and $U$ : displacement vector.

The term $j \sigma \omega A$ can be neglected because the value of the conductivity in ferromagnetic materials 
is very low. After the discretization and the assembly, we can write the algebraic equation system as follows:

$$
\left[\begin{array}{l}
{\left[K^{\mu}\right]} \\
{\left[K^{d}\right]}
\end{array}\left[K^{s}\right]-\rho \omega^{2}\left[M^{\rho}\right]\right]\left\{\begin{array}{c}
A \\
U
\end{array}\right\}=\left\{\begin{array}{c}
J_{\text {ext }} \\
0
\end{array}\right\}(9)
$$

Where: $\left[K^{\mu}\right]$ is the magnetic stiffness matrix and is defined by the following relation:

$$
\left.\left[K^{\mu}\right]=-\int_{v}\left[B_{w}\right]\left[\mu^{\sigma}\right] B_{w}\right] d v
$$

$\left[K^{S}\right]$ is the mechanical rigidity matrix and is defined by the following relation:

$$
\left.\left[K^{s}\right]=\int_{v}\left[B_{u}\right]\left[s^{H}\right] B_{u}\right] d v
$$

$\left[K^{d}\right]$ is stiffness magneto-mechanical coupling matrix given by

$$
\left[K^{d}\right]=\int_{v}\left[B_{u}\right][d]\left[B_{w}\right] d v
$$

$\left[M^{\rho}\right]$ is the inertial matrix given by

$$
\left[M^{\rho}\right]=\int_{v}\left[\mathrm{~N}_{u}\right]\left[\mathrm{N}_{u}\right] d v
$$

\subsection{Piezoelectric}

We chose the PZT-H5 ceramic as sensor material. The deformation of the stator and the electric potential in the terminals of the sensor are related by a strong electromechanical coupling as given in the following equations:

$$
\begin{aligned}
& e \nabla \bullet \nabla U-\xi^{\sigma} \nabla^{2} V=0 \\
& \rho \omega^{2} U+\nabla \bullet s^{E} \nabla U+e^{t} \nabla^{2} V=0
\end{aligned}
$$

After the discretization and the assembly we can write the system of algebraic equation as follows:

$$
\left[\begin{array}{c}
{\left[K^{\xi}\right]} \\
{\left[K^{e}\right]^{t}}
\end{array} \quad\left[K^{s}\right]-\rho \omega^{2}\left[M^{\rho}\right]\right]\left\{\begin{array}{l}
V \\
U
\end{array}\right\}=\left\{\begin{array}{l}
0 \\
0
\end{array}\right\}
$$

Where: $\left[K^{\xi}\right]$ is the matrix of electrical stiffness and is defined by the following relation:

$$
\left.\left[K^{\varepsilon}\right]=-\int_{v}\left[B_{w}\right]^{t}\left[\varepsilon^{\prime \sigma}\right] B_{w}\right] d v
$$

$\left[K^{S}\right]$ is the matrix of mechanical rigidity and is defined by the following relation:

$$
\left.\left[K^{s}\right]=\int_{v}\left[B_{u}\right]^{t}\left[s^{\prime} E\right] B_{u}\right] d v
$$

$\left[K^{e}\right]$ is electromechanical coupling matrix given by:

$$
\left[K^{e}\right]=\int_{v}\left[B_{u}\right]^{t}[e]\left[B_{w}\right] d v
$$

The tensors $s^{E}$ and $\xi^{\sigma}$ are in the strain plane and we must transform them to the stress plane using the following equations:

$$
\begin{aligned}
& \left.\left[s^{E}\right]=\left[s^{E}\right]-[e]^{t}\left[s^{E}\right] e\right] \\
& \left.\left[\xi^{\prime}\right]=\left[\xi^{\sigma}\right]-[e]^{t}\left[s^{E}\right\rfloor e\right]
\end{aligned}
$$

\subsection{Supply windings}

In three phases of stator, we have injected a current supplied by the external electrical circuit as presented in equations (22) to (24):

$$
\text { Phase A: } \nabla \times \frac{1}{\mu_{0}}(\nabla \times A)=J_{0} \cos (w t)
$$

$$
\begin{aligned}
& \text { Phase B: } \nabla \times \frac{1}{\mu_{0}}(\nabla \times A)=J_{0} \cos (w t-2 \pi / 3)(23) \\
& \text { Phase C: } \nabla \times \frac{1}{\mu_{0}}(\nabla \times A)=J_{0} \cos (w t-4 \pi / 3)(24)
\end{aligned}
$$

\subsection{Rotor}

In the rotor bars there is a current induced by the relative motion of rotating field with respect to rotor position. We have the following partial differential equation:

$$
\text { jo } \omega_{r} A+\nabla \times \frac{1}{\mu^{\sigma}}(\nabla \times A)=0
$$

with: $\omega_{r}$ : is the pulsation of the rotor currents

\subsection{The air-gap}

In the air gap the magnetic induction is proportional to the magnetic field, so we can write:

$$
\nabla \times \frac{1}{\mu_{0}}(\nabla \times A)=0
$$

\section{RESULTS AND DISCUSSION}

Before talking about the obtained results, it is necessary to claim the position of the piezoelectric sensor in the rotor and the stator is very important because some perturbation in the magnetic flux repartition can be induced by the presence of this sensor. The induced perturbation is highlighted in Fig. 2. The incorporation of our piezoelectric sensor can perturb the operation of the machine by the prevention of magnetic flux flow in ferromagnetic materials because piezoelectric ceramics have a paramagneticbehaviour [27]. However, the magnetic potential lines did not penetrate into the inside of the slot as shown in Fig. 2. So this situation leads to choose the sensor position to be in the inside of the slot in order to avoid all possible disruption of the potential lines and hence the degradation of the machine operation. In order to correctly position the sensor, it is necessary to take into consideration first the field disturbance. The preliminary results represented in Fig. 3. Show that the value of the magnetic induction is minimal in the slots. However, the total displacement is maximal in the boundary of the slot as represented in Fig. 3. In the other hand, this figure highlights also that the applied magnetic field induces two deformation domains situated symmetrically according to the $x$ axis. For these reasons we propose to install two sensors shift by $180^{\circ}$ relative to both each others in the slots as shown in Fig. 5.

The polarization of the piezoelectric materials plays an important role and has a direct influence on the voltage at the sensor terminals. The polarization of the piezoelectric materials can be chosen according the $x$ axis or $y$ axis leading to the visualization of two components $u$ and $v$ of displacement along the $x$ and $y$ axis. In our case the maximum displacement along the $x$ axis is greater than the $y$ axis as represented in Figs. 6 and 7 . respectively. So the polarization of our piezoelectric 


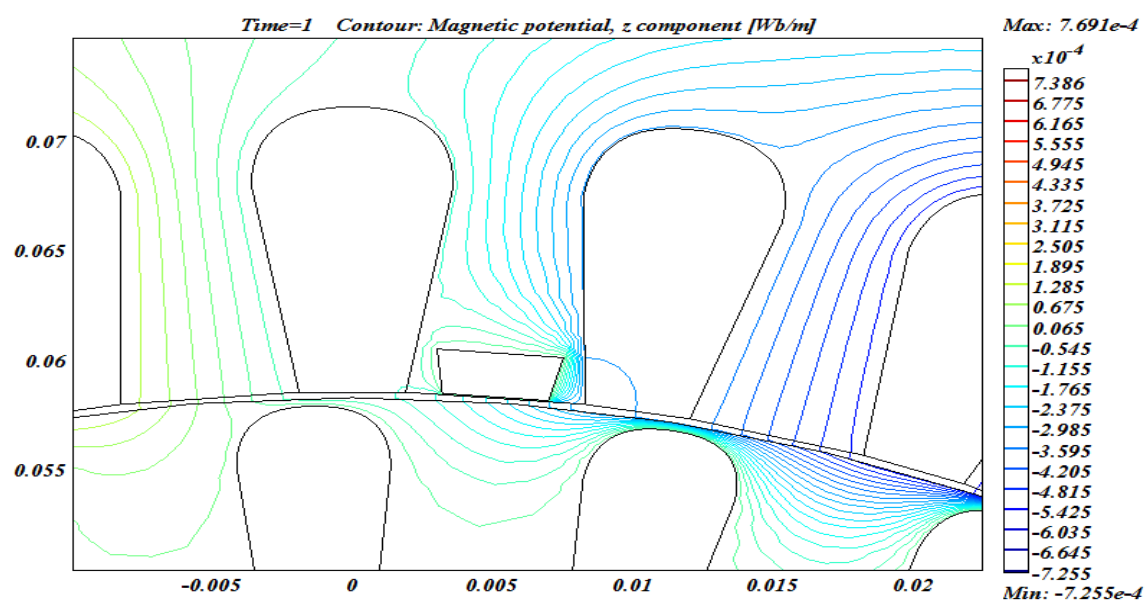

Fig. 2. Disturbance of the magnetic potential lines by the piezoelectric sensor

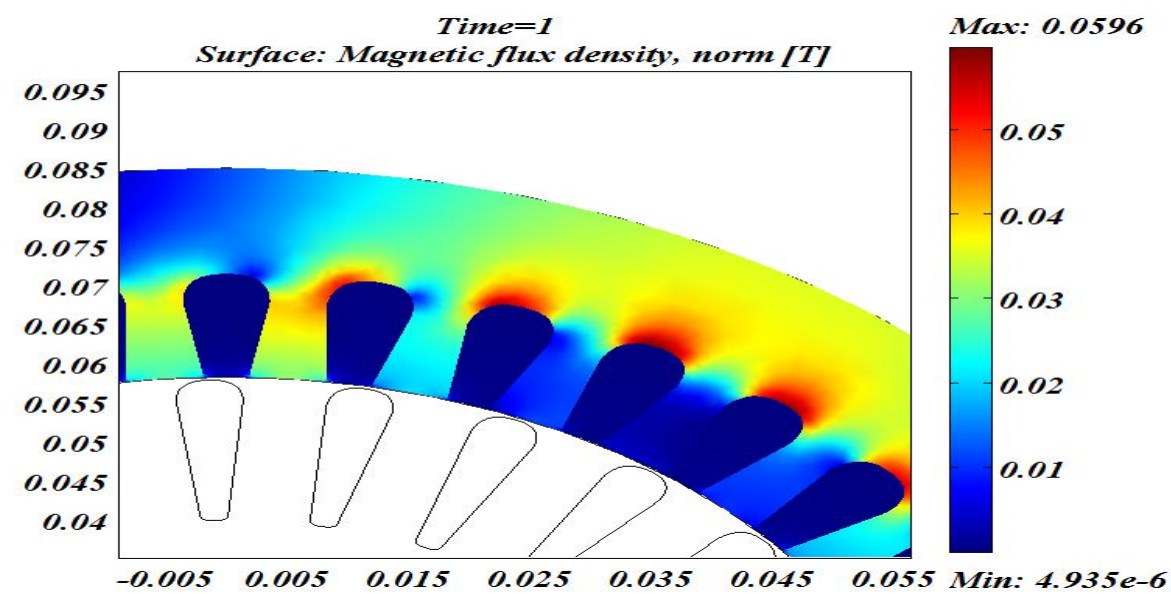

Fig. 3. Magnetic induction in the stator

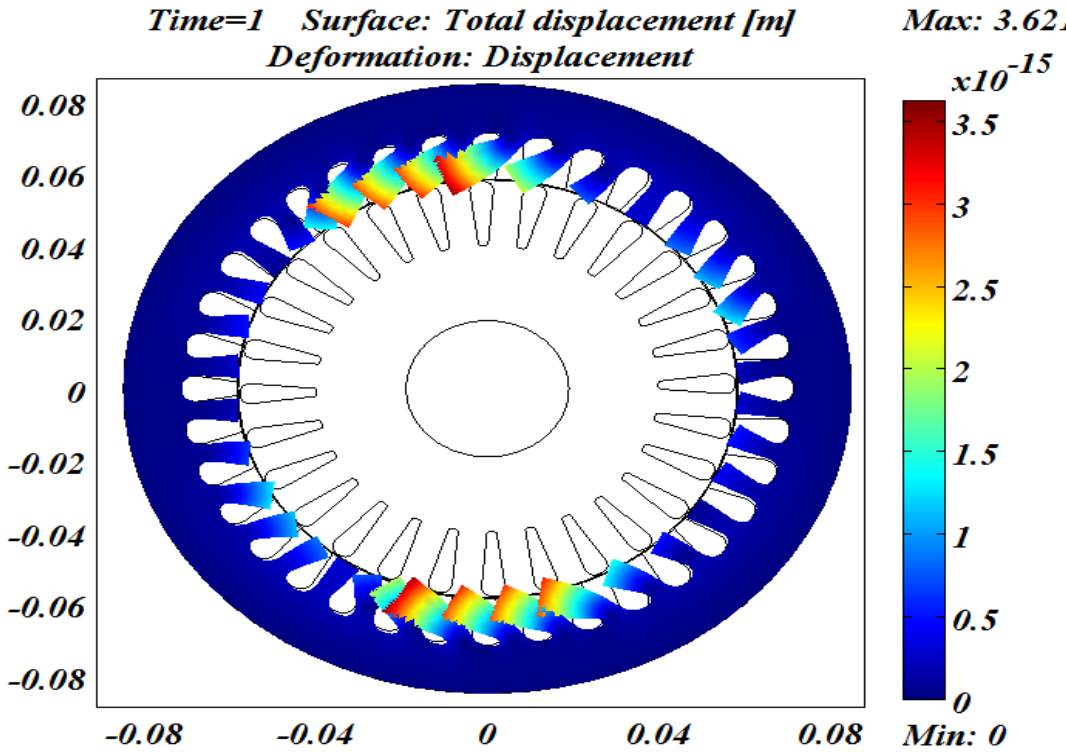

Fig. 4. Total displacement 


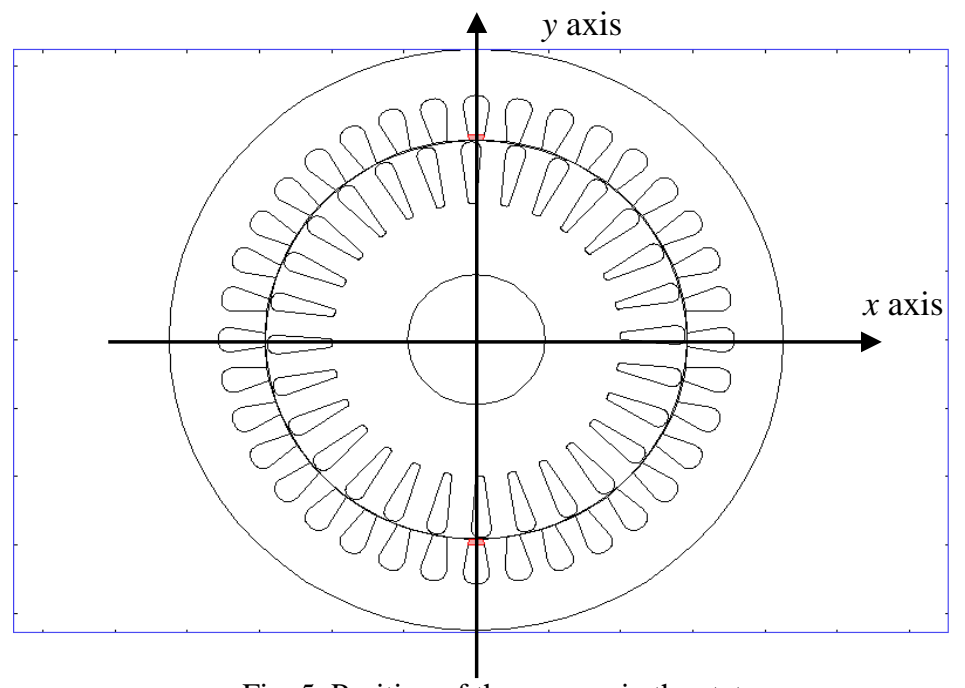

Fig. 5. Position of the sensors in the stator

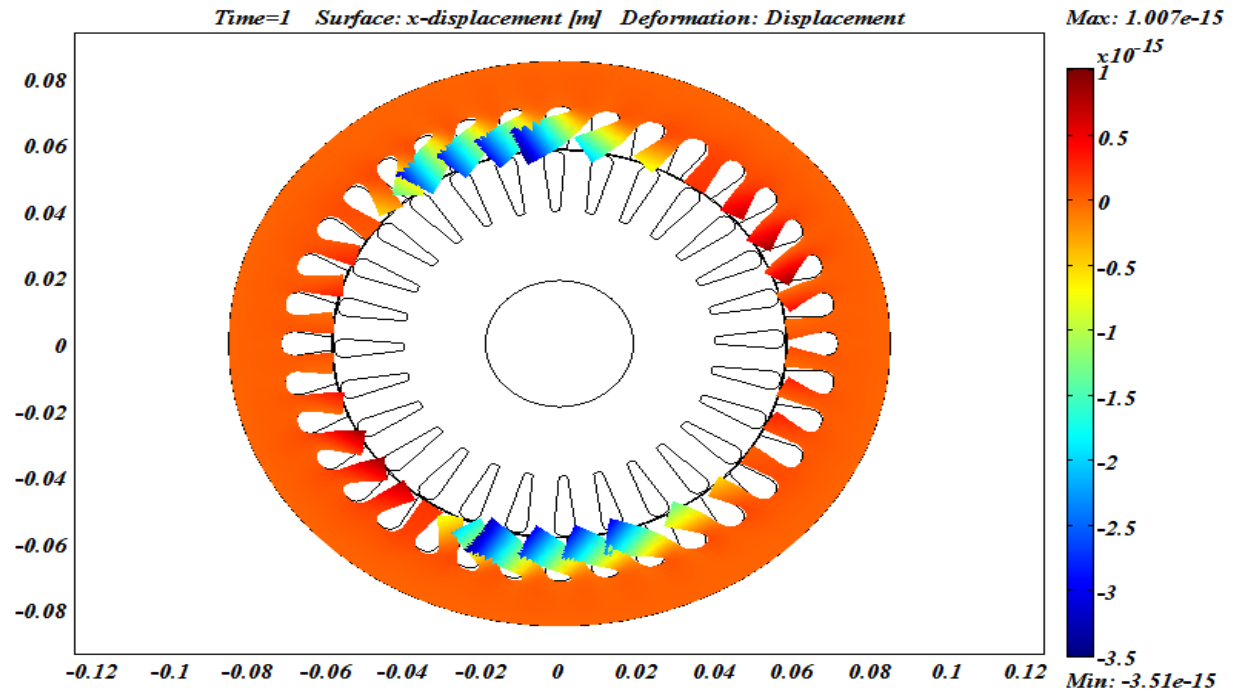

Fig. 6. Displacement $\boldsymbol{u}$ along the $x$ axis

sensor material must be along the $x$ axis and the coupling matrix will be in the form:

$$
e=\left[\begin{array}{ccc}
d_{12} & d_{12} & 0 \\
0 & 0 & d_{22}
\end{array}\right]
$$

and the electromechanical coupling tensors will be:

$$
e=\left[\left[\begin{array}{cc}
0 & 0 \\
d_{12} & 0
\end{array}\right]\left[\begin{array}{lc}
0 & 0 \\
0 & d_{22}
\end{array}\right]\right]
$$

With:

$d_{12}$ and $d_{22}$ are coefficients of electromechanical coupling.

According to the position of the piezoelectric sensor in the slot of stator, represented in Fig. 7, we can detect a voltage that we call $V_{s}$. This voltage is detected when the machine is healthy (without any defects). The results of the magnetic potential lines are presented also in Fig. 8 and are not disturbed by the presence of the piezoelectric sensors in the slots consolidating then our previous choice analyzed previously. The voltage
$V_{s}$ at the terminals of the piezoelectric sensor has the form represented in Fig. 8. This voltage has sinusoidal form and follows the total displacement. In Figs. 10a to 10c we have presented the voltage in the terminal of both used sensors for machine presenting cut-off of one phase or two phases together. The cut-off ofone phase gives the same signal in both sensors because their symmetrical position. As the sensors are placed in the phase C, the recorded signals present magnitude bigger than the healthy machine with the same frequency. However, when the cut-off of phase is done in phase A or B, the signals are completely distorted.

When the cut-off of phases is occurred in two phases together, the behaviour is quite different. The obtained results of this case are displayed in Figs. $10 \mathrm{~b}$ and 10c. The recorded signal by both sensors is the same in the case when the cut of is occurred in phase $\mathrm{B}$ and phase $\mathrm{C}$ in the same time, but when the cut-off is located in the phases $\mathrm{A}$ and $\mathrm{C}$ or $\mathrm{A}$ and $\mathrm{B}$ the recorded signals by each sensor is opposite to the other. 


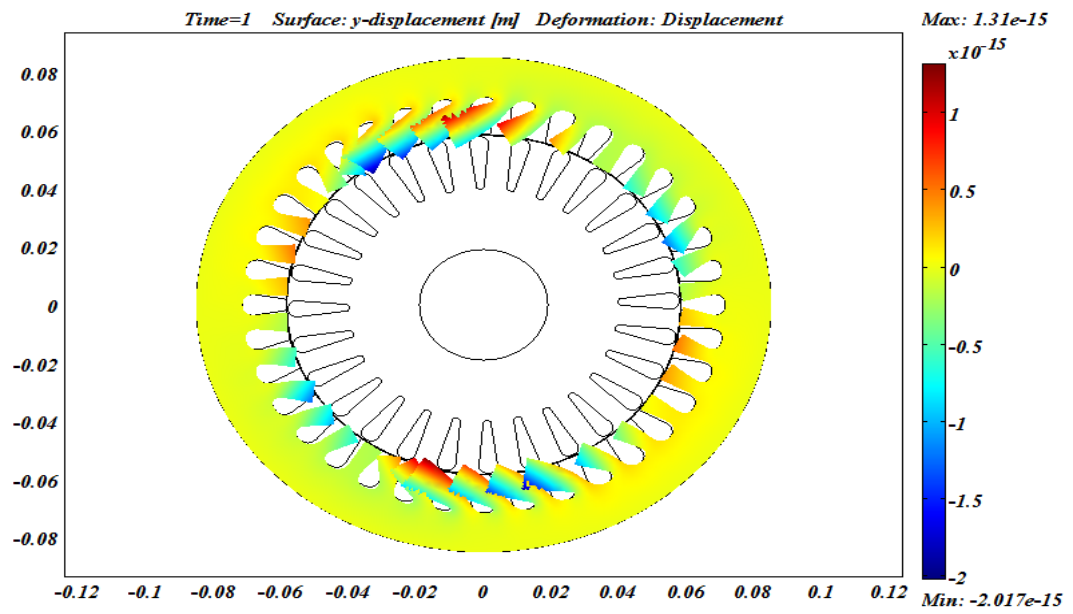

Fig. 7. Displacement $v$ along the $y$ axis

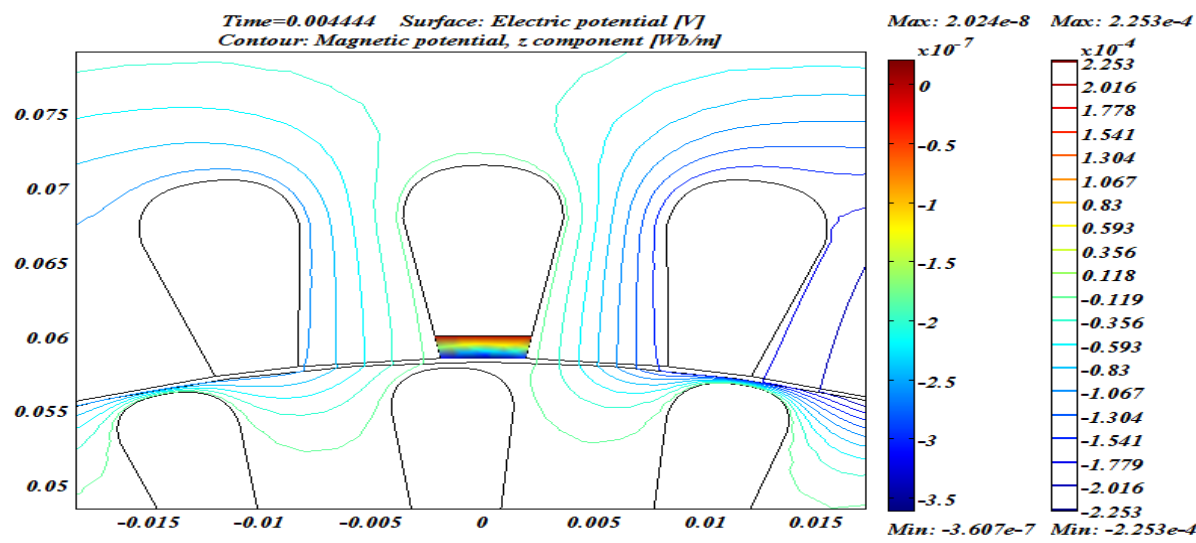

Fig. 8. The voltage $V_{s}$ in the sensor

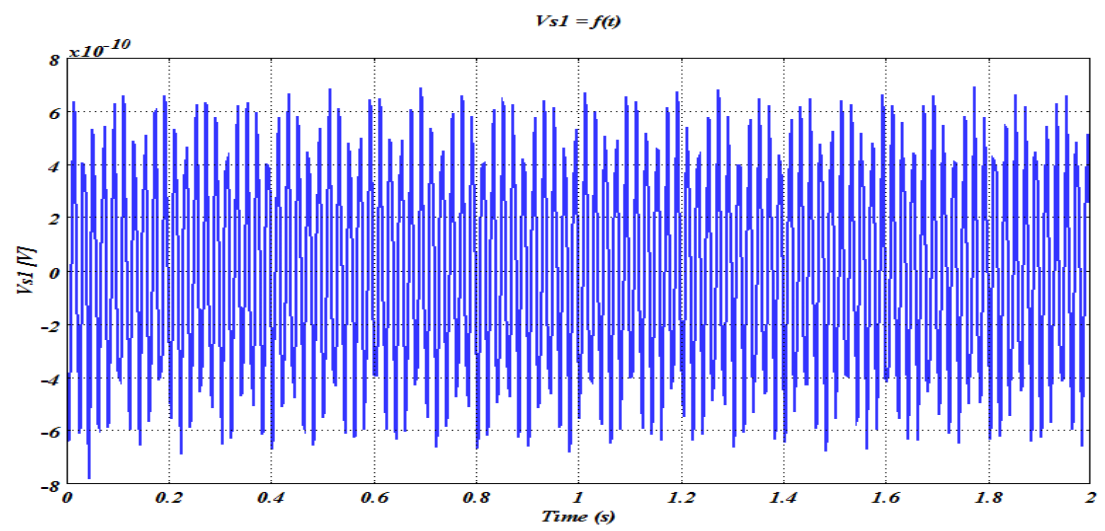

Fig. 9. Voltage generated between the sensor terminals Vs

The detection of the broken rotor bars is put also in evidence in our study. It is well highlighted that the detection of the broken rotor bars is no longer possible by the sensors that are installed in the stator. So we have proposed in this part of the work to add another sensor in the rotor to detect the defaults in rotor bars. For the position of the latter, we have followed the same philosophy as in the stator. First we chose the sensor position far from the magnetic saturation for not disturb the operation of the machine. The repartition of the magnetic induction represented in Fig. 11 allowed us to choose the position between the bars. Furthermore, Fig. 12 represents that the total displacement has a maximum in the higher boundaries of bars. This distribution requires that the sensor position must be in the middle of the poles as shown in Fig. 13. 
a)

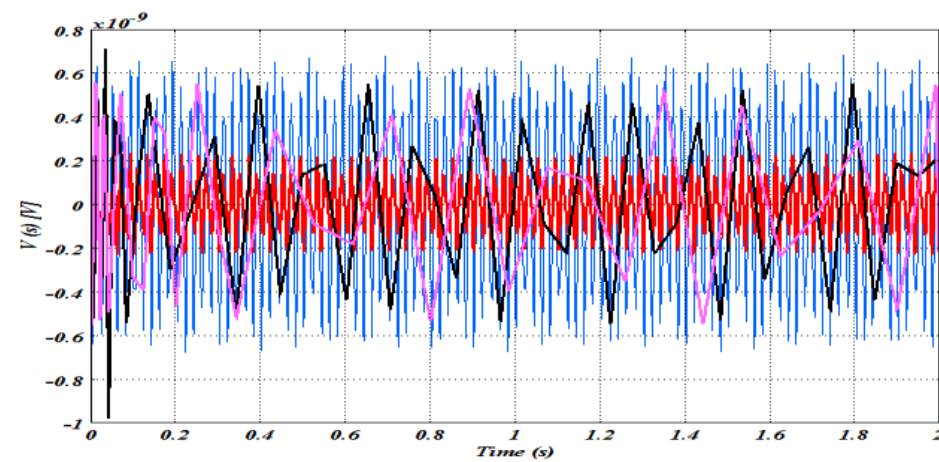

b)

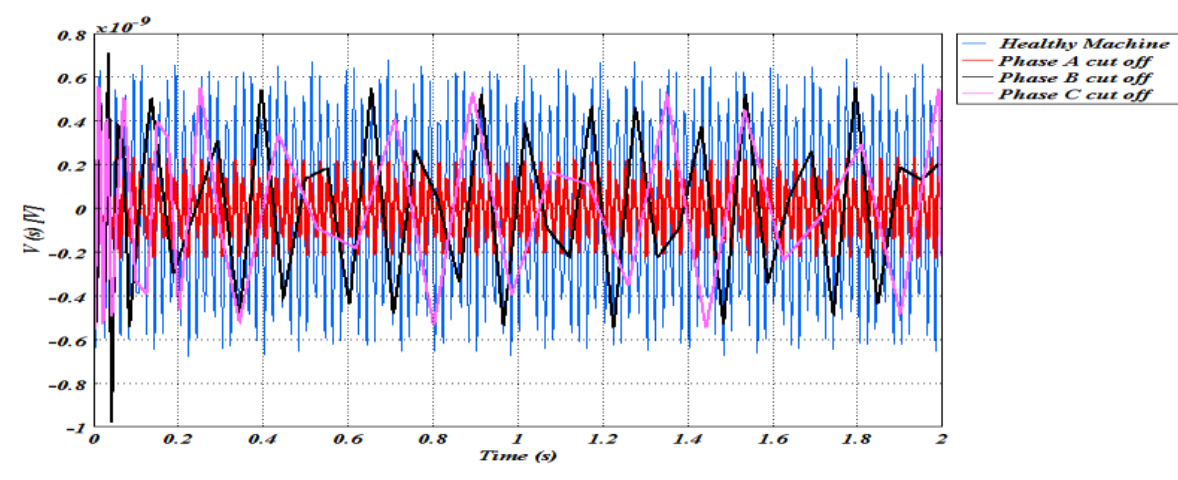

c)

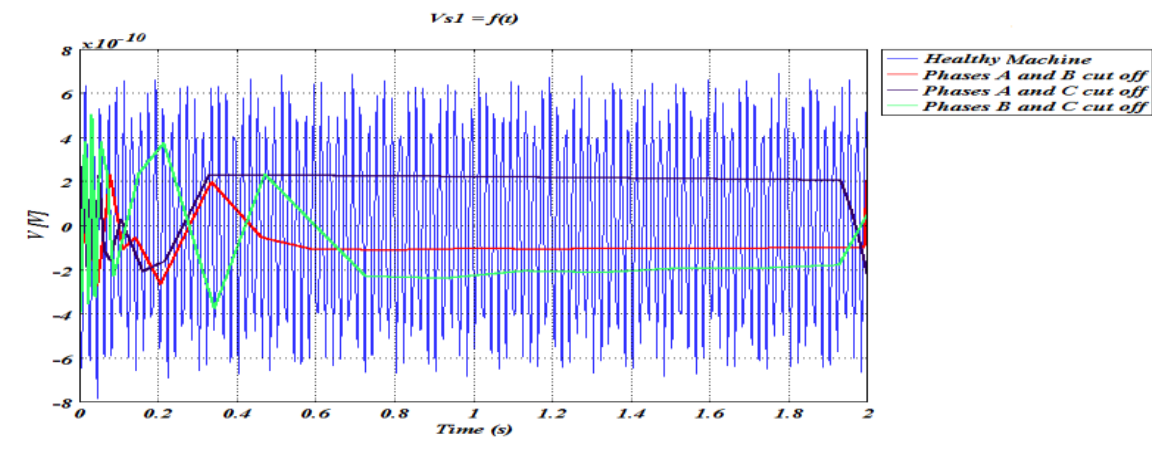

d)

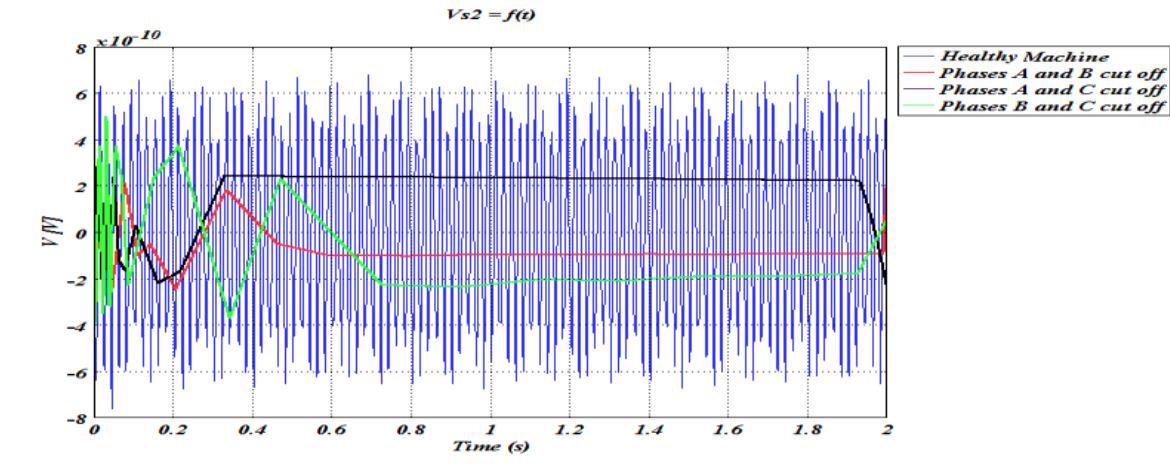

Healthy Machine
Phase A cur off
Phase B cut off

Phase C Cut off

Fig. 10. Voltages created in the sensors with the different cuts of the phases (a) First sensor with a phase cut off (b) Second sensor with a phase cut off (c) First sensor with two phases cut off (d) Second sensor with two phases cut off 
The direction of the applied polarization of material has often a determinant part to get a maximum displacement. Thus a small analysis of the determination of the displacements according to the $x$ and $y$ axis ( $u$ and $v$ ) must be conducted.
The obtained results are respectively represented in Fig. 14 and 15. As long as $u$ greater than $v$ we will polarize the sensors along the $x$ axis as in the stator.

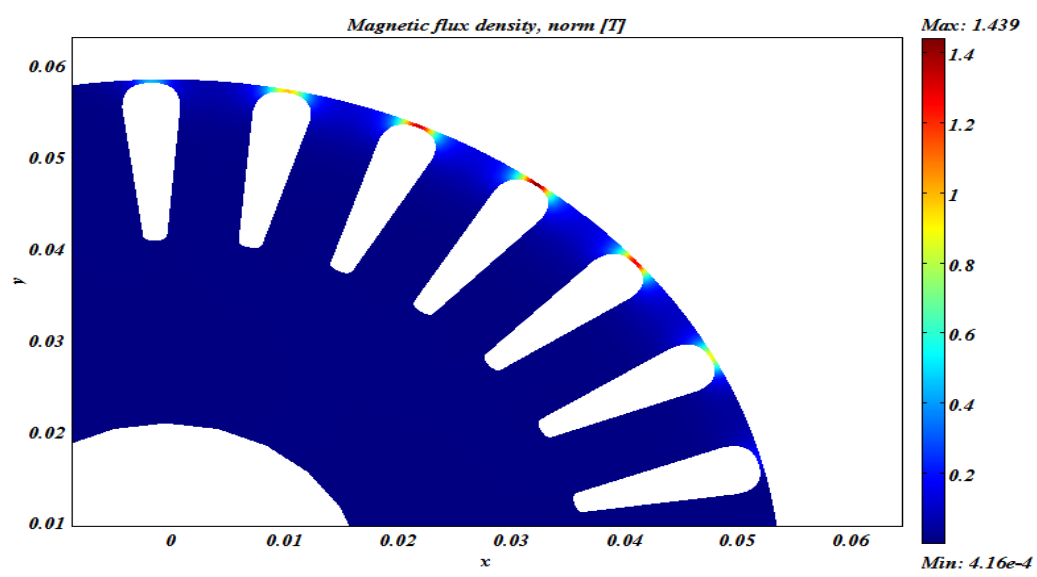

Fig.11. Magnetic induction to the rotor

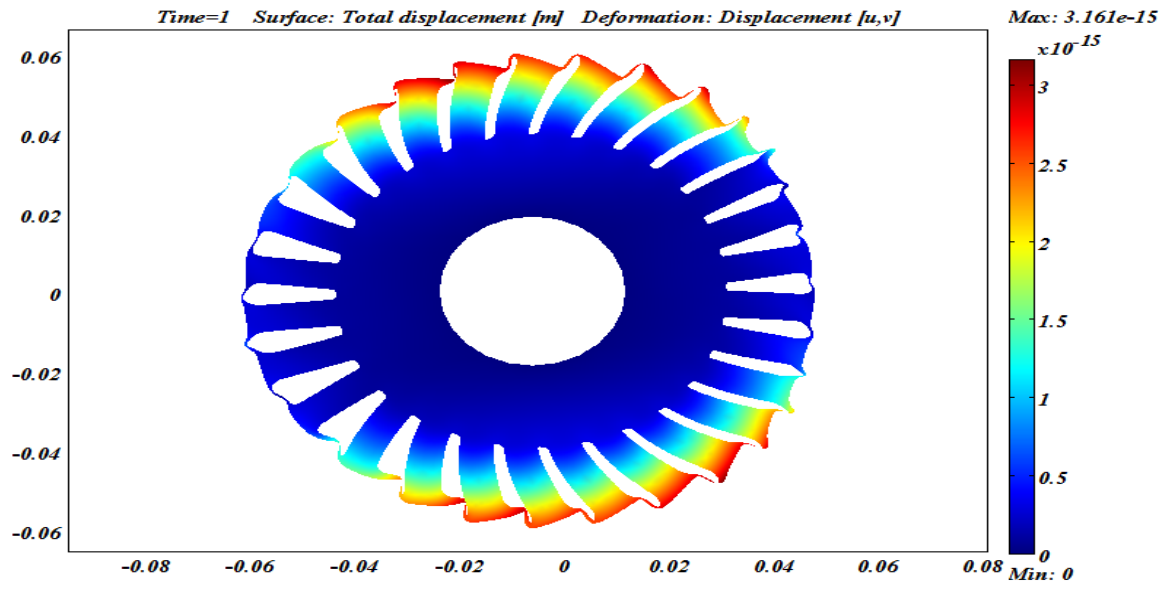

Fig. 12. Total displacement

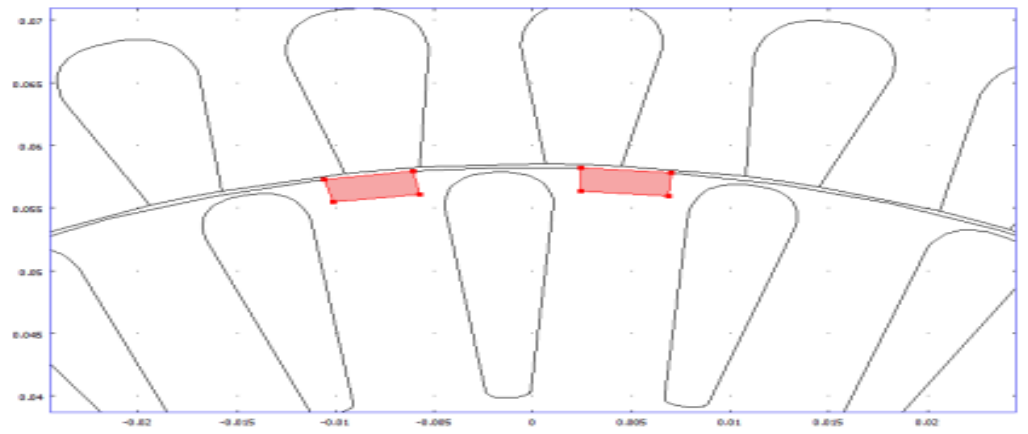

Fig. 13. Position of the sensors 


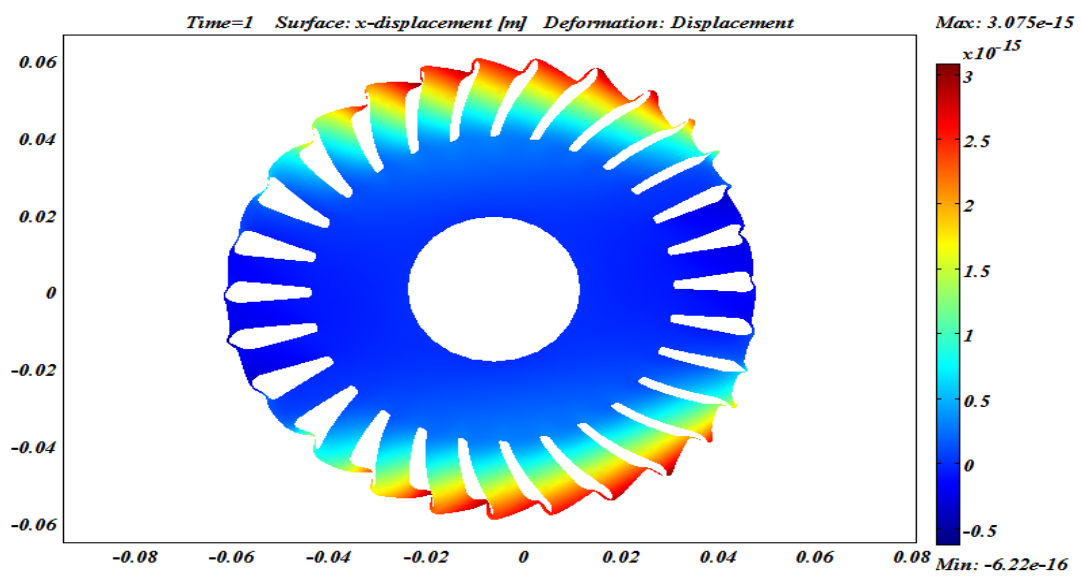

Fig. 14. Displacement $\boldsymbol{u}$ along the $x$-axis

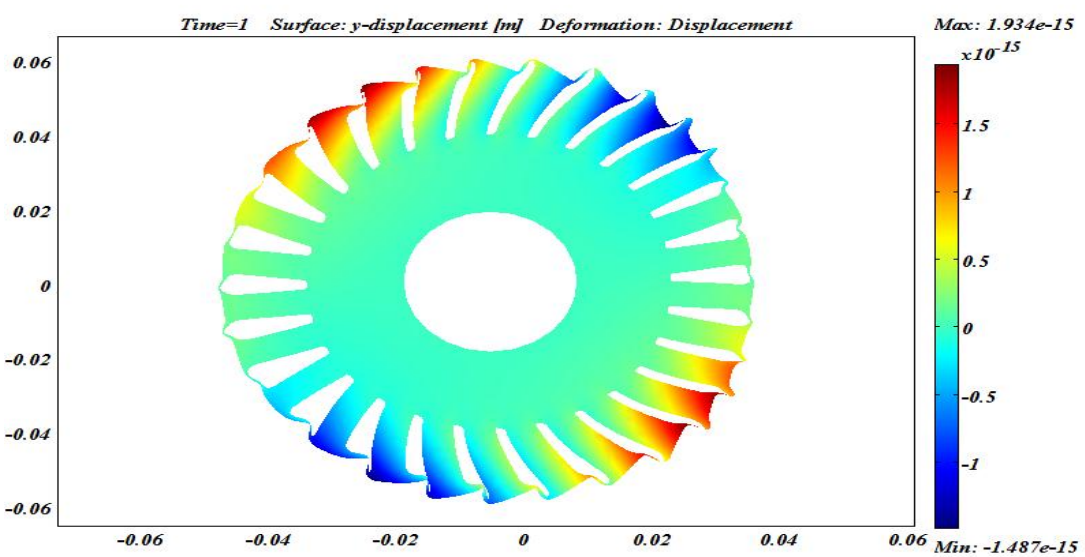

Fig. 15. Displacement $v$ along the $y$ axis

According to the piezoelectric sensor installation between the bars Fig. 16 we can detect a voltage that we call $V_{r}$ where the machine is healthy. This voltage has a sinusoidal form and follows the maximal total displacement Fig. 18.

It is well known that the main defaults that occurred in the rotor are the break of bars. This phenomenon is the responsible of the machine vibration. Furthermore one bar or more can be broken simultaneously, thus our analysis must cover all the possible cases. In the first step one broken bar is studied and then tree bars are considered to be broken together. The position of the broken bars can be adjacent or no Fig. 17. All these possible cases give results summarized in the Fig. 18. This figure shows that the generated voltage in the terminal of the piezoelectric sensor presents higher values than the healthy case. This increase is due the penetration of the magnetic flux more into the rotor because of the absence of currents induced in the cut magnetic bars as shown in Fig. 19. The penetration of the flux is important when the broken bars are in adjacent positions as shown in Fig. 19. This important penetration leads to higher value of the generated voltage in the sensor as can be seen in Fig. 18.
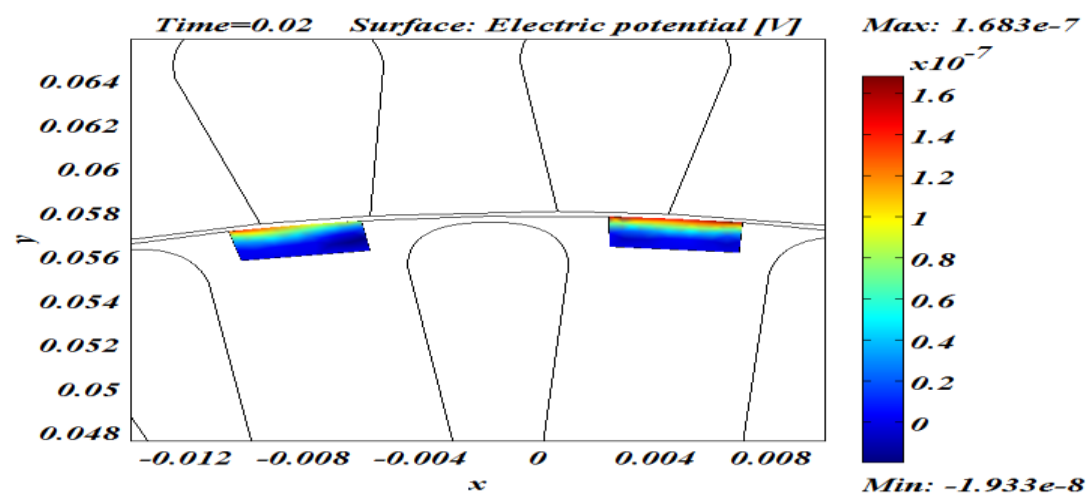

Fig. 16. The voltage $V_{r}$ in the sensor 


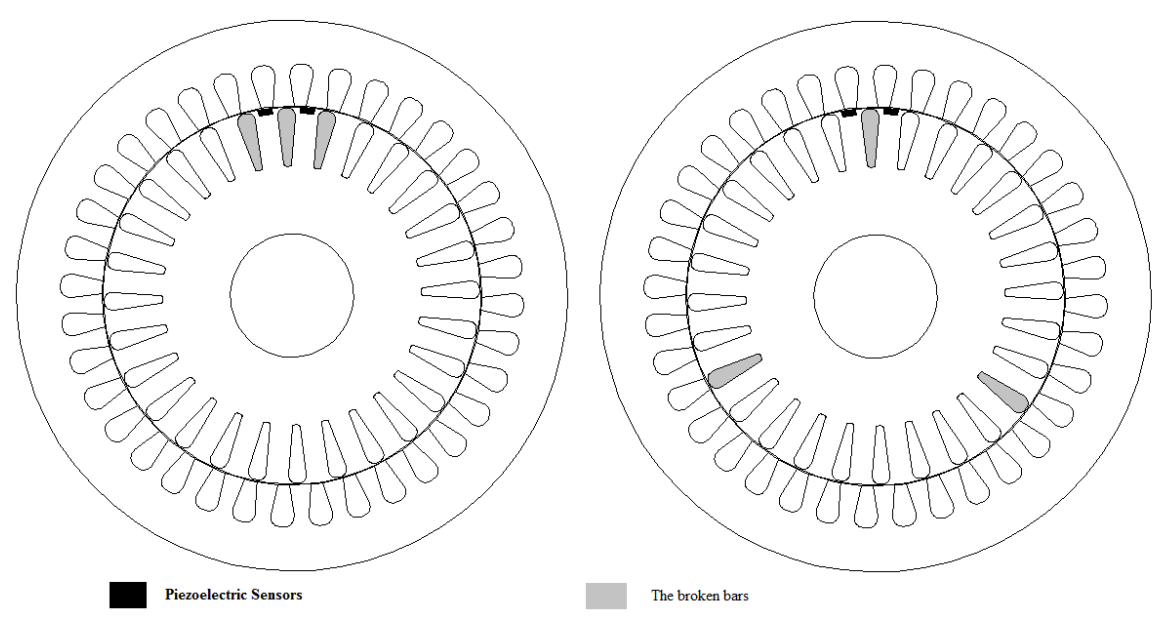

Fig. 17. Position of adjacent and nonadjacent broken bars and position of piezoelectric sensor
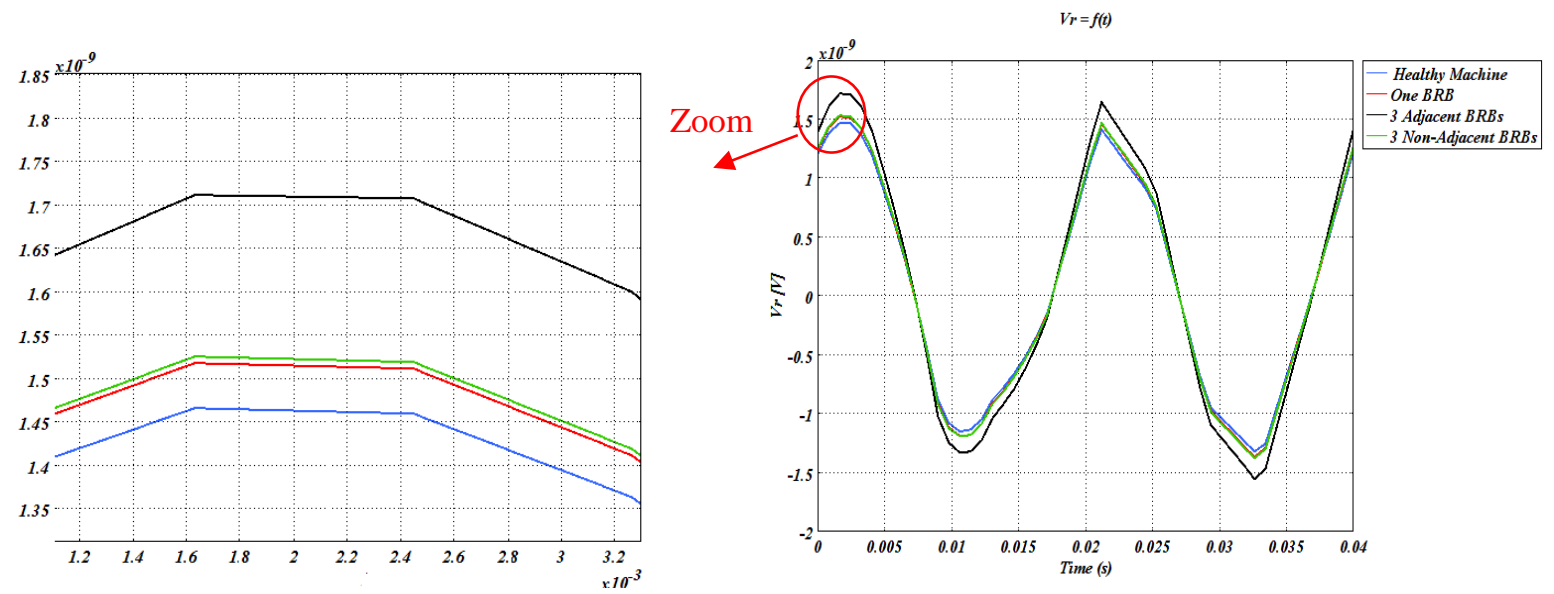

Fig. 18. Voltage created in the sensors with the different phase's cuts

a)

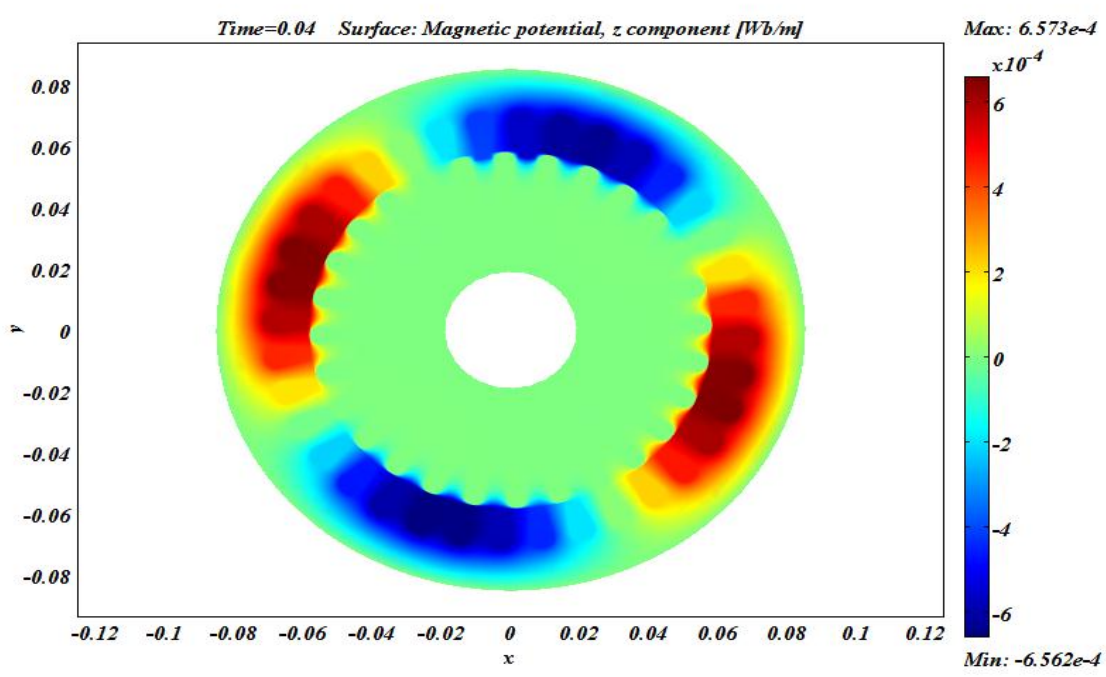


b)

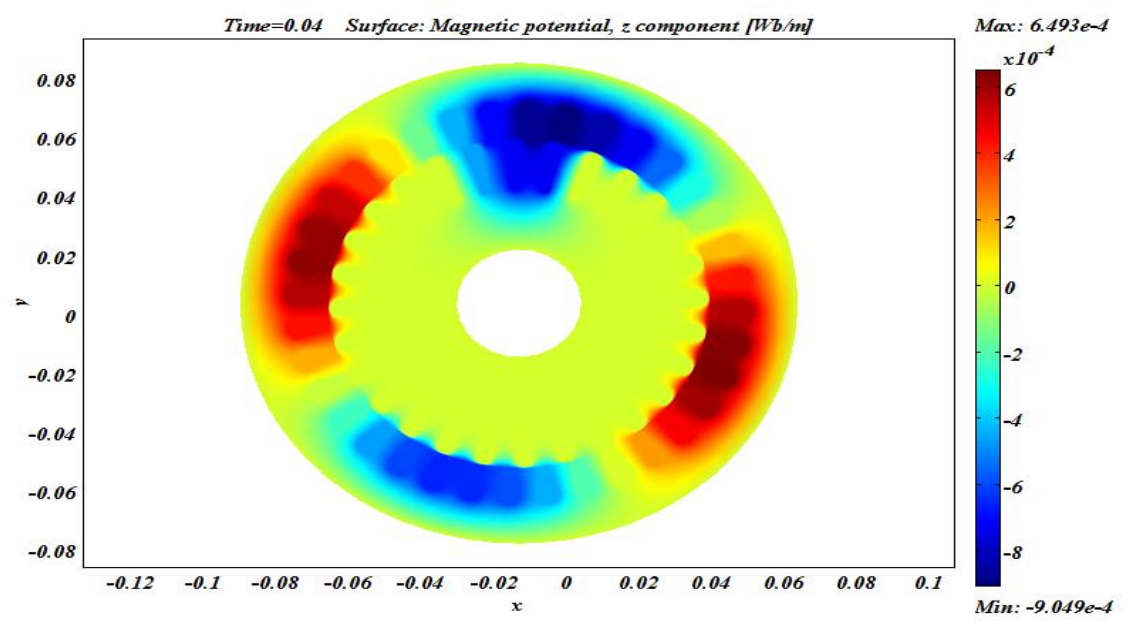

Fig. 19. Magnetic potential in rotor (a) without defect (b) with defect

\section{CONCLUSION}

In this paper, we propose a new method for the diagnosis of defects in asynchronous machines based on the exploitation of smart materials. We have modeled the strong electromechanical and magneto-mechanical coupling phenomena through the laws of piezoelectric and piezomagnetic behaviours. The resolution of the partial differential equation is taken part with the finite element method, and then we exploited them to detect the defects in the three-phase asynchronous machine. The principle of our approach is based on the observation of electric potential induced on the electrodes of piezoelectric layer installed in the stator or in the rotor by their deformations under the effect of the magnetostriction behaviour of the make-up materials of the asynchronous machine. Anyway, it was compared with the reference value where the machine healthy for locality the cut of coil stator or broken rotor bars.

\section{REFERENCES}

1. Faiz J, Moosavi M. Eccentricity fault detection From induction machines to DFIG-A review. Renewable and Sustainable Energy Reviews, 2016;

https://doi.org/10.1016/j.rser.2015.10.113

2. Thomson WT, Fenger M. Current signature analysis to detect induction motor faults. IEEE Ind. Appl. Mag. 2001; 7(4): 26-34.

3. Kim J, Shin S, Bin Lee S, Gyftakis KN, Drif M, Cardoso JM. Power spectrum based detection of induction motor rotor faults for immunity to false alarms. Energy Convers. 2015; 30(3): 1123-1132. https://doi.org/10.1109/TEC.2015.2423315

4. Rodriguez PVJ, Negrea M, Arkkio A. A simplified scheme for induction motor condition monitoring. Mech. Syst. Signal Process, 2008; 22(5): 1216-1236.

5. Liu Z, Zhang X, Wei Y. Rotor faults diagnosis way for induction motors based on PQ transformation, IEEE Int, Conf. Control Autom. ICCA, 2008; 10(2): 1067-1071.

6. Chattopadhyaya A, Sengupta S, Chattopadhyay S. Analysis of stator current of induction motor used in transport system at single phasing by measuring phase arigle, symmetrical components, skewness, kurtosis and harmonic distortion in park plane. IET Electr. Syst. Transp, 2014;4(1):1-8.

7. Tavner PJ. Review of condition monitoring of rotating electrical machines. IET Electr. Power Appl, 2008; 2(4): 215-247.

8. Ebrahimi BM, Faiz J. Diagnosis and performance analysis of three-phase permanent magnet synchronous motor with static, dynamic and mixed eccentricity. IET Electr. Power Appl, 2010; 4(1): 5365.

9. Kaikaa MY, Hadjami M, Khezzar A. Effects of the simultaneous presence of static eccentricity and broken rotor bars on the stator current of induction machine. IEEE Trans. Ind. Electron, 2014; 61(6): 2942-2942.

10. Yang C. Screening of false induction motor fault alarms produced by axial air ducts based on the space harmonic induced current components, IEEE Trans. Ind. Electron, 2015; 62(3): 1803-1813. https://doi.org/10.1109/TIE.2014.2331027

11. Lee S, Hong J, Bin Lee S, Wiedenbrug E, Teska M, Kim H. Evaluation of the influence of rotor axial air ducts on condition monitoring of induction motor. IEEE Energy conversion congress and exposition (ECCE), 2012: 3016-3023.

https://doi.org/10.1109/ECCE.2012.6342360

12. Yang C, Kang TJ, Hyun D, Bin A, Lee J, AntoninoDaviu JA. Reliable detection of induction motor rotor faults under the rotor axial air duct influence, IEEE Trans. Ind. Apl, 2014; 50(4): 2493-2502. https://doi.org/10.1109/TIA.2013.2297448

13. Sadeghian A, Ye Z, Wu B. Online detection of broken rotor bars in induction motor by wavelet packet decomposition and artificial neural network, IEEE Trans. Instrum. Meas, 2009; 58(7): 22532263.

14. Boughrara K, Takorabet N, Ibtiouen R, Touhami O, Dubas F. Analytical analysis of cage rotor induction motors in healthy, defective, and broken bars conditions. IEEE Trans. Magn, 2015; 51(2): 1-17. https://doi.org/10.1109/TMAG.2014.2349480 
15. Moses AJ. Effect of stress on the magnetic properties of grain-oriented silicon iron magnetized in various directions. IEEE Trans. Magn, 1981; 17(6): 2872-2874.

16. Gourdin C, Hirsinger L, Barbier G, Billardon R. Experimental identification of the coupling between the anhysteretic magnetic and magnetostrictive behaviours. Journal of Magnetism and Magnetic Materials, 1998; 177(1): 201-202.

17. Belahcen A. Magnetoelasticity, magnetic forces and magnetostriction in electrical machines. Ph. D, Helsinki University of Technology, 2004. Finland.

18. Schneider C, Richardson J. Biaxial magnetoelasticity in steels. Journal of Applied Physics, 1982; 53(11):8136-8138.

19. Pearson J, Squire PT, Maylin MG, Gore JG. Biaxial stress effects on the magnetic properties of pure iron. IEEE Trans. Magn, 2000; 36(5): 32513253.

20. Maurel V. Influence de l'état mécanique multiaxial induit par la découpe sur les propriétés d'usage des tôles magnétiques. Thèse de doctorat, Ecole Normale Supérieure de Cachan, 2002. France.

21. Curie J, Curie P. Développement, par pression, de l'électricité polaire dans les cristaux hémièdres à faces inclinées. Comptes rendus de l'Académie des Sciences, 1880,91: 294-295.

22. Curie J, Curie P. Sur l'électricité polaire dans les cristaux hémièdres à faces inclinées. Comptesrendus de l'Académie des Sciences, 1880; 91:383387.

23. Regaz A, Zegnini B, Mahi D, Boukezzi L. Static and harmonic behavior of piezoelectric beam bending actuators. Electrotechnica, Electronica, Automatica, (EEA), 2017; 65(4): 30-36.

24. Regaz A, Boukezzi L, Zegnini B, Mahi D. Contribution to the study of piezoelectric beam bending actuator in harmonic mode. 5th International Conference on Electrical Engineering (ICEE-B), 2017:1-5. https://doi.org/10.1109/ICEE-B.2017.8192191

25. Regaz A, Boukezzi L, Zegnini B, Mahi D. Contribution to the study of piezomagnetic materials. 4th International Conference on Electrical Engineering (ICEE-B), 2015: 1-4. https://doi.org/10.1109/INTEE.2015.7416833

26. Azoum K, Besbes M, Bouillaut MF. 3D FEM magnetostriction phenomena used coupled constitutive laws, International Journal of Applied Electromagnetic and Mechanics, 2004; 19: 367371.

27. Nguyen TT. Modeling with finite elements of magneto-electric composite materials, $\mathrm{PhD}$ thesis, University of Paris, 2011. (in French)

28. Srinivasa Rao K, Srinivas G, Srinivas-Prasad MVVK, Srinivas Y, Shudheer B, Venkateswar Rao A. Design and simulation of MEMS based piezoelectric shear actuated beam. American J. Mater. Sci, 2012; 2(6):179-184. https://doi.org/10.5923/j.materials.20120206.04

Received 2018-02-10

Accepted 2018-07-17

Available online 2018-07-18

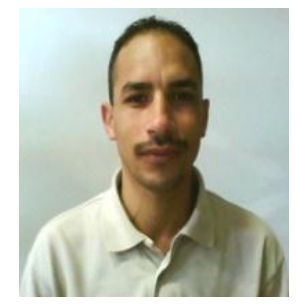

Amar REGAZ was born in Djelfa (Algeria), on january 1, 1980.

He graduated the University ZianAchour, Faculty of Electrical Engineering in Djelfa (Algeria), in 2006. He received the Magister in magnetic-electrical systems from the polytechnic military School of Bordjbahri (Algeria), in 2009. He is Professor at the University Zian-Achour, in Djelfa (Algeria). His research interests concern: numerical Analysis of FEM, power electronics, and electric machines.

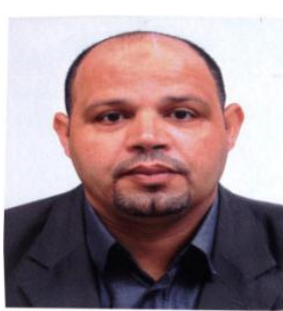

Boubakeur ZEGNINI was born in Laghouat, Algeria on January 25, 1968. He received the Dipl. Eng. Degree in electrical engineering from the ENSET of Laghouat (Algeria) in 1991, the M.Sc. degree from the institute of Electrical Engineering, University Center of Laghouat (Algeria) in 2001. He received the $\mathrm{PhD}$ degree in electrical engineering from Mohammed Boudiaf Science and Technology University of Oran - USTMB Oran (Algeria) in 2007.

He is full Professor at the University of Amar Telidji, in Laghouat (Algeria). His research interests concern: Material characterization, Insulation materials, High voltage, Modelling, Simulation, Artificial intelligence, power systems

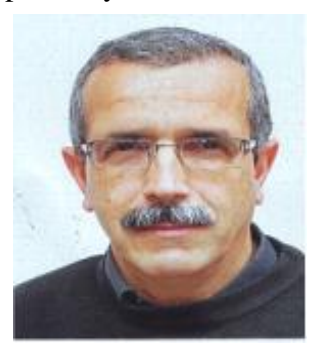

Djillali MAHI was born in Tiaret (Algeria), on June 25, 1959. He graduated the University of Science and Technology, Faculty of Electrical Engineering in Oran (Algeria), in 1982. The Dr-Ing degree from university of Paul Sabatier in Toulouse (France), in 1986 . He received the $\mathrm{PhD}$ degree in electrical engineering from the University of Djillali Liabes of Sidi Belabbes (Algeria), in 2002. He is full Professor at the University of Amar Telidji, in Laghouat (Algeria). His research interests concern: High voltage materials, power electronics, electric machines, and thermal plasma.

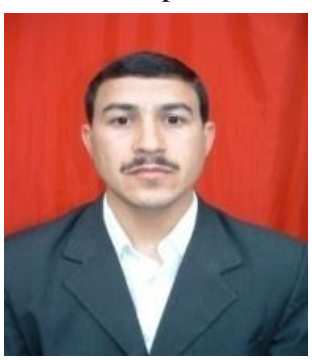

Larbi BOUKEZZI was born in Batna (Algeria) in January 1974. He has received the degree of Engineer in 1997 in electrical engineering from Ecole Nationale Polytechnique (ENP) of Algiers, and he has obtained the Masterand the Doctorate in Science degrees in 2000 and 2007 respectively from the High Voltage laboratory of ENP. He is currently a full professor in Djelfa University where he gives lectures in electrical engineering and supervising researches in field of high voltage insulations. He is also Head of Dielectric Materials group of Materials Science and Informatics Laboratory, MSIL. His principal research areas include high voltage insulation cables, thermal and electrical ageing of solid insulations, electrical field calculation and application of intelligent techniques in prediction and diagnostic of the high voltage insulations. 